\title{
Labor intensity in context of information and communication technologies sustainable development
}

\author{
Elena Krasova* \\ Vladivostok State University of Economics and Service, 690014 Vladivostok, Russia
}

\begin{abstract}
The information and communication technologies (ICT) impact on labor intensity is one of the actual, but understudied interdisciplinary issues of modern science and practice. Observations and analysis of labor processes in context of the ICT use point out the increase in labor intensity. The purpose of the research is to identify key sources of workers' labor intensity growth under the ICT development, regardless of the field of professional activity. The article highlights such sources as increase in work strenuousness, growth of number of labor functions and operations, lengthening working day, and also change in work and rest regime. A special focus is on the problem of «leisure time colonization». An $\cap$ shaped correlation between labor intensity and productivity is presented. The general conclusion that unlimited growth of labor intensity is inconsistent with the sustainable development and effective development of human capital is made.
\end{abstract}

\section{Introduction}

Over the past decades, information and communication technology (ICT) has significantly changed people's lifestyle and work format. At home and at work, people use various gadgets and devices that enable searching and processing information, expanding business possibilities and personal communications, making transactions in real time, getting an education, etc. The ICT in industry are manifested in automation and robotization processes, in artificial intelligence systems. All this induces many researchers to talk about sustainable development under «a new reality - globalization 4.0» [1], «revolution that will fundamentally change our life, our work and our communication» [2], «future without job» $[3,4]$, «era of intellectualization» [5], «technological alternation of the modern mind» [6] and free creative labor predominance [7].

Despite the growth in information production and consumption we observe today, modern literature tends to exaggerate the ICT positive effects and underestimate the negative ones. This is especially true for such field of researches as labor organization, where, in our opinion, some faraway and probabilistic problems attract too great interest and attention. At the same time, many urgent everyday problems concerning the computerization and informatization processes in economic activity are rather poorly

\footnotetext{
*Corresponding author: elena_krasova@rambler.ru
} 
studied. Many experts, inspired by the ICT potential, actively discuss an upcoming technological unemployment, new «digital» professions and a problem of «free time, which will be too much soon» [3]. But now, millions of workers around the world feel burned out due to ultra-high work intensity, computer syndrome, information pollution and permanent compelled communications. "While the tedium of office work is nothing new, all-day, everyday computer work is a fairly recent and growing phenomenon. This is a horrible existence masquerading as the apex of a civilized world» [8].

World Health Organization identifies labor intensity as one of the most important social components that determines the level of public health and the level of socio-economic development. Work-related health problems lead to economic losses of $4-6 \%$ of GDP in most countries [9]. Extension of researches of the labor intensity growth factors in context of the ICT use is relevant, firstly, in terms of increasing labor productivity and ensuring the national economy sustainable development. Secondly, it is very important in terms of workers' safety, their physical, intellectual, psychological and social potentials salvation. On the basis of these potentials, a human capital which is so necessary to work with ICT is steadily developing and growing.

The purpose of the research is to identify key sources of workers' labor intensity growth under the ICT development at the present stage. A specific scientific and practical task, the research can help solve, is optimization of labor organization and human capital management in a steadily developing information economy.

\section{Materials and methods}

The research is fundamentally based on the labor organization theory, which examines the labor intensity as a complex category that includes organizational, economic and physiological components. This category defines amount of physical, mental and psychical energy expended by a worker per a working time unit. On the one hand, high labor intensity can make labor productivity grow. On the other hand, high energy expenses of workers can negatively affect their health, making their work hard and stressful, regardless of the profession and activity type. Labor intensity depends on many factors, but influence of such important organizational and technological factor as the ICT is underexplored. This is because it is a recent problem in science and this problem lacks much attention now. Under studying the ICT impact on labor intensity we can highlight the following main research areas in modern literature.

1. The ICT influence on workplaces' functions in various fields of activity. The subject here is replacement of hard and harmful labor with machines; facilitation of working conditions under changing technologies; perspectives of automation, robotization and digitalization in different industries $[10,11]$.

2. The ICT influence on labor intensity by changing content of knowledge and varying requirements for workers. Here, focus is on skills and abilities required in the era of informatization and digitalization; on «intellectualization», «digitalization» and «creativity» of labor; on hard \& soft skills combination and brain efforts intensification that is consistent with the skills $[12,13]$.

3. Influence of working conditions with ICT on employees' health and well-being through the work \& rest regime. Scientists confirm the health deterioration under the technological, informational and communication stressors impact $[14,15]$. A spatial \& temporal deformation of boundaries of the work \& rest organizational field, including the problem of «leisure time colonization» and «leisure fetishization» is on a special focus today $[16,17]$. 
On the whole, most economists and engineers believe that ICT makes work easier and significantly improves work efficiency. At the same time, medics, psychologists and educators convincingly demonstrate negative consequences of the ICT use.

The research is methodologically based on general methods of economics and institutional analysis, including systematization, generalization, abstraction, comparisons, and expert assessments.

\section{Results and discussion}

Here we consider a general mechanism of work format change, taking into account the ICT factor.

Information and computer technologies have made the work with information more organized and efficient by assuming a number of complex auxiliary functions, for example, calculations, data processing, algorithming, unification, copying, etc. However, this does not cancel a fact of people's work with information at all. Both in earlier historical periods, and nowadays, any work is based on the perception, processing and use of professional information. The only difference is that today the active circulation of information leads to its rapid obsolescence and to need to obtain new information so that to maintain and/or increase labor productivity. The processing speed and the processed information amount increase proportionally. This naturally increases informational, sensory and psychoemotional burden on a worker. At the same time the worker bears full responsibility for decisions he makes on the basis of the information obtained on his workplace.

In today's literature there is a prevailing opinion about inevitable labor intellectualization as a result of the ICT implementation. We can find even some apologetics of mental labor as the highest form of human activity. This opinion, as a rule, does not take into account the high degree of mental work monotony because of continuous and steady attention concentration and brain activity mobilization in conditions of physical activity deficit. Moreover, being along with non-standard and creative operations that are visible for intellectual work, everyday routine operations taking the largest share in working process are out of consideration scope, although such invisible, but no less necessary operations are typical for overwhelming majority of professions. «In any profession we can distinguish its iconic social visibility and invisible routine activities which take most of working time» [18]. Thus, the ICT objectively stress a worker's central nervous system, and it leads to labor strenuousness increase.

ICT has accelerated executing a large number of organizational and communication tasks, such as doing correspondence, notifying \& sending messages, writing \& registering different applications, ordering \& paying for goods and services, and other bureaucratic tasks. «Technology has simplified a number of operations so much that now we do them ourselves, although before it used to require separate workers» [19]. However, to simplify is not to abolish. Now most of these work operations are being done by workers themself. Within a working time unit there are a lot of «simple and effective» deeds that create a backlog and work not for the final goal, but for ensuring the labor process. On the one hand, process actions can be standard (formulaic or similar actions), for example, sending a mail, writing \& agreeing an application, entering data into a program, etc. In this case, additional work routinization emerges, even if a creative work is formally being done. On the other hand, an individual acts in a multi-situational environment, where templates sometimes do not work, for example, computer is freezing, software is not responding, document approval procedure has been changed, etc. Here a worker has to spend additional efforts to rectify the non-standard situation. Often, the efforts and time wasted for ensuring current labor process are much more than ones spent on a result. Eventually, the worker 
does more and catches less. This is a kind of Pareto law strengthening, concerning to modern labor.

A duplication of work with traditional and digital technologies is one of the important factors in increasing labor intensity nowadays. This is especially true for jobs not directly related to the IT sector. The current stage of informatization and digitalization is incomplete, transitional; therefore work with ICT is well combined with traditional work format. We don't observe the purely digital economy. We can see a multi-structured economy in most countries, including developed ones. In particular, business experience of Russian enterprises and organizations shows frequent use of computers, software and paperwork in combination. This is due to high costs of the ICT objects implementation for many business entities, to labor organization imperfection and incomplete information security systems [20]. Combination and duplication of old and new technologies increase a number of labor functions and operations. In addition, transition to ICT requires studying instructions for software, administering accounts, registering in various electronic systems, being a member of different professional online communities, etc. This all takes a lot of time and efforts, although it may seem very simple to a modern person.

Today, advantages of implementation of different ICT objects into production are being actively discussed and substantiated. The objects - computers, automatic machines, robots, etc. - reduce costs, improve product quality, eliminate the human factor, optimize the workspace. However, everyday practice often shows us the opposite situation: imperfections of the ICT and/or the ways they use are clearly manifested. The ICT equipment is periodically broken down; the software efficiency \& speed largely depend on developer's workmanship, equipment \& software compatibility, server power and other factors. Turning off the electricity can stop a work at all. An ordinary worker is able to solve not all of these troubles and not always. If they are out of his control he has to wait for a technical service or take the work home to continue.

Thereby, under investigating the mechanism of the ICT impact on labor processes, we have noticed the significantly growing number of labor process operations and functions per a working time unit. Scientists have fixed a paradox: «We thought that new technologies would free us from work. But they freed us up for even more work» [17]. At the same time, wages often depend on work results, on goals or plans achievement. The disbalance between spent time and paid time makes workers to strengthen their work density and increase work hours amount at the expense of leisure time of course.

Today «leisure time colonization» is a civilizational problem that goes beyond just «I had no enough time to finish it». ICT enabled to break the connection between workers and their workplaces, but have placed workers in a constant and at once intermittent work cycle [17]. We highlight the following most relevant sources of labor intensity growth through the free time colonization:

- Irregular working hours, multitasking and soi-disant work flexibility, when a part of the work is taken home in order to redistribute physical and psychological tension.

- Necessity of permanent learning and training, because requirements are imposed not on labor operation any more, but on worker. He must not and does not want to lag behind the technology, but he can train only out of his working hours as a rule.

- Communication in real time. ICT is erasing the spatial boundaries of business communication. The «always in touch» strategy is good for business efficiency, but it greatly increases the labor strenuousness.

- Self-identification in the social environment. Just doing official duties is not enough for modern individual: his look and life style must be consistent with the standards of his professional and social surroundings in order to win in interpersonal professional competition. Desire for a professional and social status has a dominant influence on all other spheres of his life. 
We should note that today the $24 / 7$ work principle is presented by business as a way to the highest level of productivity, creativity and innovation. It reflects a conceptualization of work as a hobby, a desire to be «the best version of myself». However, such total mobilization of an individual's professional and personal resources, soi-disant selfentrepreneurship, leads only to sustained constant stress, which ends with professional and personal burnout.

So, the ICT let increase efficiency of some labor functions and operations. But this efficiency increases along with the labor intensity, which has its own temporal and physiological limits. Beyond the limits all normal conditions for human capital's functioning and reproduction are destroyed. This stipulates an $\cap$-shaped correlation between labor intensity and productivity: intensity growth beyond the physiologically acceptable level can turn into productivity fall (figure 1).

Labor productivity

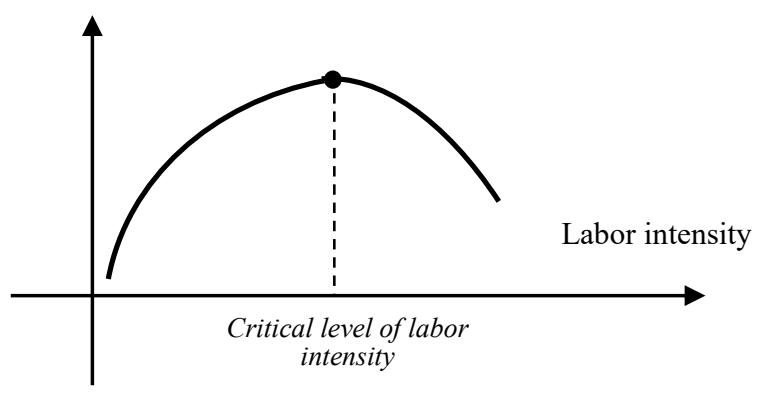

Fig. 1. Correlation between labor intensity and labor productivity.

We can assume that at present humanity is on the ascending segment of this curve: «digital euphoria» is raising force; labor intensity is growing; «work supervalue» principle is encouraged as a factor of human self-realization. However, there is a risk of public health deterioration and even a social tension growth if an acceptable level of labor intensity is not maintained. By the way, according to a Russian research results, only $15 \%$ of adults are always ready to learn [21]. And it doesn't reduce business development potential [22]. Today, there is no reason to believe that human labor in any profession will ever become absolutely free and creative, because the most of the labor functions and operations are routine by their nature and are carried out under organizational, technological and communication stressors. Not all jobs can become a hobby: work by vocation is much less common than work for remuneration. Therefore «only a minority works at the craftsmanship level» [18]. As for self-entrepreneurship, this is a kind of social dystopia conceptualized by leading business structures. Its formation will most likely collide with the natural defense mechanism of human survival, since «the self-entrepreneur is in a temporal imbalance that strikes his existence entirely» [16].

\section{Conclusions}

As a result of the research, we can draw the following conclusions.

1. The ICT use in different fields of professional activity contributes to increase in labor intensity. The ICT influence is manifested through the labor strenuousness growing, adding the number of labor functions and operations, lengthening the working day, as well as changing the work and rest regime.

2. Work with large amounts of information and monotony of mental efforts enhance the labor strenuousness. The working time is lengthened because of growing number of labor 
functions and operations performed by a worker within his workplace, duplication of work with standard and computer technologies, and the ICT imperfection. The «leisure time colonization» is a special contributor when a worker spends his leisure time on activities directly or indirectly related to work by means of the ICT.

3. Labor intensity and productivity have an $\cap$-shaped correlation. Unlimited growth in labor intensity is inconsistent with the sustainable development concept and effective development of human capital. In order to prevent the negative consequences of ultra-high labor intensity, it is necessary to develop adequate health-saving technologies for optimal labor organization and human capital management.

\section{References}

1. A. A. Porokhovskiy, USA \& Canada: Ec., Pol., Cult., 49(8), 5-24 (2019)

2. K. Schwab, The fourth industrial revolution (WEF Publ., Geneva, Switzerland, 2016)

3. A. Hines, Foresight and STI Governance, 13(1), 19-30 (2019)

4. M. Ford, Rise of the robots: technology and the threat of a jobless future (Basic Books Publ., NY, US, 2015)

5. O. V. Nedoluzhko, Journal of Social Sciences Research, 3, 228-234 (2018)

6. G. Small, G. Vorgan, iBrain: surviving the technological alternation of the modern mind (William Morrow Paperbacks Publ., NY, US, 2008)

7. W. D. Holford, Futures, 105, 143-154 (2018)

8. M. Heid (2019) https://elemental.medium.com/

9. Protecting workers' health, WHO (2021) https://www.who.int/

10. A. E. Varshavsky, V. V. Dubinina, MIR, 11(3), 294-319 (2020)

11. A. Akaev, T. Devezas, Yu. Ichkitidze, A. Sarygulovd, Technological Forecasting and Social Change, 167, 120675 (2021)

12. E. V. Levina, Economics and Society: Contemporary Models of Development, 9(2), 177-192 (2019)

13. N. A. Tsareva, S. Y. Omelyanenko, Revista De La Universidad Del Zulia, 11(31), 131$140(2020)$

14. A. Khedhaouria, A. Cucchi, Journal of Business Research, 101, 349-361 (2019)

15. N. A. Tsareva, Z. V. Yakimova, A. A. Vlasenko, Dilemas Contemporaneos Educacion Politica Y Valores, 6, 81 (2019)

16. A. Corsani, Logos, 25(3), 51-71 (2015)

17. P. Arora. Logos, 25(3), 88-119 (2015)

18. N. Klowait, M. Erofeeva, Logos, 29(1), 53-84 (2019)

19. N. B. Afanasov, Galactica Media: Journal of Media Studies, 1, 43-61 (2019)

20. T. V. Bubnovskaya, M. E. Vasilenko, N. Y. Titova, V. V. Pekhotsky, Opcion, 34(872), 457-470 (2018)

21. Life Long Learning (2021) https://rg.ru/

22. E. V. Krasova, Azimuth of Scientific Research: Econ. and Adm., 9(3(32)), 215-218 (2020) 